\begin{tabular}{|c|c|c|}
\hline$A r$ & $\begin{array}{c}\text { European Association for the } \\
\text { Development of Renewable Energies, Environment } \\
\text { and Power Quality (EA4EPQ) }\end{array}$ & $\begin{array}{l}\text { International Conference on Renewable Energies and Power Quality } \\
\text { (ICREPQ'12) } \\
\text { Santiago de Compostela (Spain), 28th to 30th March, } 2012\end{array}$ \\
\hline
\end{tabular}

\title{
Effect of Superconducting Fault Current Limiters on Successful Interruption of Circuit Breakers
}

\author{
M. Firouzi ${ }^{1}$, S. Aslani ${ }^{1}$, G. B. Gharehpetian ${ }^{3}$ and A. Jalilvand ${ }^{4}$ \\ 1,2 Department of Electrical Engineering, Islamic Azad University, Abhar branch, Abhar, Iran \\ E-mail: m_firoziabhari@yahoo.com,shahab.aslani89@gmail.com \\ ${ }^{3}$ Electrical Engineering Department, Amirkabir University of Technology, Tehran, Iran \\ Phone/Fax number: +98 21640 6469, e-mail: grptian@aut.ac.ir \\ ${ }^{4}$ Electrical Engineering Department, University of Zanjan, Zanjan, Iran \\ E-mail: ajalilvand@znu.ac.ir
}

\begin{abstract}
The penetration of DG systems in distribution systems can result in the increase of the short circuit current level. The application of the fault current limiter (FCL) would not only decrease the stress on network devices, but also can offer a connection to improve the reliability of the power system. There are various types of FCLs, which are made of different superconducting materials and have different designs. There are several kinds of SFCLs, which can be classified in three types such as the resistive type, the inductive type and bridge type SFCL. In this paper, the transient recovery voltage (TRV) analysis, based on the electromagnetic transient program (EMTP), is used to investigate the behavior of the each three types SFCL installed in an electrical distribution grid. Simulation results show that the TRV can be damped in the presence of the resistive and bridge type SFCL during fault clearing period.
\end{abstract}

\section{Key words}

Superconducting Fault Current Limiter, Transient Recovery Voltage, Rate of Rise of Recovery Voltage (RRRV), Circuit Breaker

\section{Introduction}

With the growth of the demand for electric power, the electric power systems are interconnected each other to increase the reliability of power supply. However, fault current levels increase beyond capabilities of existing equipments in some points of grids. Therefore, all equipments especially, circuit breakers have to have a short circuit rating capable of withstanding this level. Usually, handling these increasing fault currents requires the costly replacement of equipments or imposition of changes in the configuration. But, the splitting of substation may decrease the operational flexibility and system reliability. An alternative solution is the usage of FCLs to reduce the fault current to withstanding level of existing circuit breakers. So, the existing equipments can still be used to protect the power system [1]-[2].

Also after being limited by the FCL, the current is interrupted at its current zero by a circuit breaker. After the interruption of the fault current, a transient recovery voltage (TRV) appears across the contacts of the circuit breaker. To perform a successful interruption, the circuit breaker must withstand against the TRV without reestablishment of the arc between the contacts.

An ideal FCL should have the following features [1-3]:

- Zero impedance and power losses at normal operation,

- Large impedance in fault conditions,

- Quick appearance of impedance when fault occurs,

- Fast recovery after fault removal,

- Reliable current limitation at determined fault current and

- Good reliability.

Superconducting Fault Current Limiter (SFCL) offers a solution to these problems with many significant advantages. The application of the SFCL would not only decrease the stress on device but also offer an interconnection to secure the network. They can improve reliability and stability of power systems by reducing the fault current. There are several kinds of SFCLs, which can be classified in three types such as the resistive type, the inductive type and bridge type SFCL. Each type of SFCL has its merits and demerits [1-5]. Many studies have focused on the topology and capability of SFCLs. The inductive type SFCL is able to suppress the voltage drop and limit the fault current. The resistive type SFCL can consume the energy of the fault current and limit it. This capability can improve the power system stability. The bridge type SFCL is a kind of SFCL, which has zero impedance under the normal condition and large impedance under fault condition. Its advantage is the fault current limitation without any delay and smoothing the surge current waveform. But, it can not limit the steady state fault current. Among the parameters of the FCL, the magnitude of the limiting impedance and its merits affects the current-limiting performance of the FCL much more than the other parameters. In other 
words, depending upon the kind of the FCL and its merits, the insertion of the FCL in to the power system can result in more severe interrupting problems. Therefore, it is important to study the interrupting behavior of circuit breakers in the presence of the kinds of FCLs [5-8]. In this paper, a comparative study of the interrupting behavior of circuit breakers in the presence of three types such as the resistive type, the inductive type and bridge type SFCL have been carried out.

\section{SFCL Concept}

Several designs have been considered for the SFCL which are based on different superconducting materials. The resistive SFCL is simply connected in series with the network; the inductive SFCL is based on a transformer with a superconducting shielding tube in the secondary. The bridge-type SFCL consists of a diode-bridge and superconductor as limiting function.

\section{A. Resistive SFCL Model}

A resistive SFCL utilizes resistance increase upon quench of a superconductor. It has advantages such as simpler structure, smaller size, and possibly lower capital cost than other types. During normal operation, the superconducting element is in its superconducting state and the normal load current passes with theoretically no loss. In the case of a short circuit, the circuit current rises sharply and the superconductor undergoes a transition to its normal state, so a certain value of nonlinear resistance is created by selfsensing and self-triggering, thus limiting the fault current level. A non-linear resistive model was used to analyze the features of a resistive FCL prototype with EMTP simulator in this paper. Its behavior under normal operation and short-circuit conditions in a test circuit was investigated by computer simulation using the EMTP program. As the scaled $\mathrm{I}-\mathrm{V}$ curve shown in Fig. 1, the resistance variation is represented by the gradient of the curve [9-10].

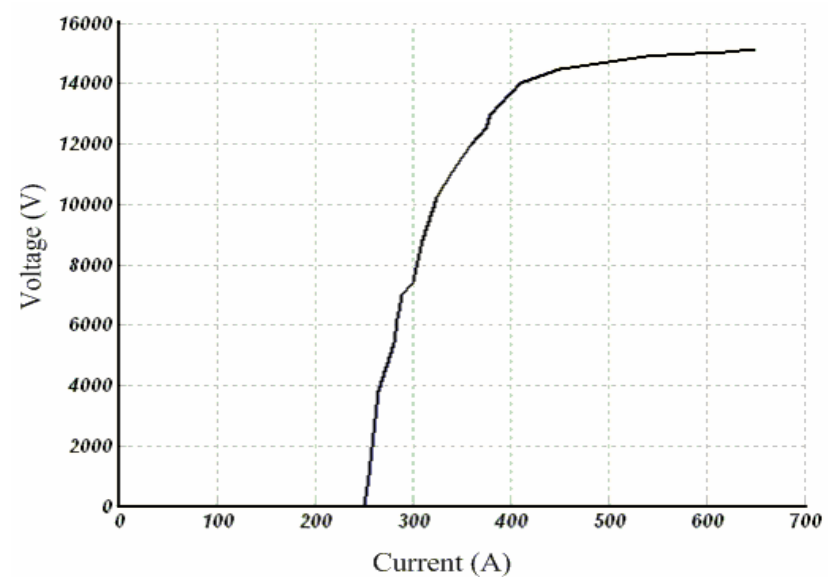

Fig. 1. V-I curve of resistive FCL

\section{B. Inductive SFCL Model}

In the model of the inductive FCL, a capacitance $C_{P}$, is connected in parallel with the limiting coil to simulate a stray capacitance appearing in the winding of the coil. The stray capacitance $C_{P}$, has so much higher impedance than the inductance $L_{F C L}$ that the impedance $Z_{F C L}$ is equal to the impedance of the inductance $L_{F C L}$. Fig. 2 shows the inductive SFCL model, used in this paper [11].

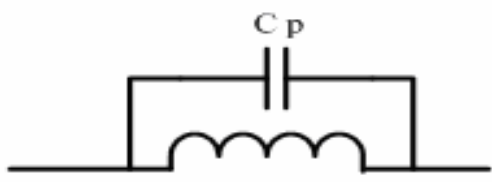

$\mathrm{L}$ FCL

Fig. 2. Inductive SFCL model

\section{B. Bridge-Type SFCL Model}

Fig. 3 shows the three-phase bridge-type SFCL, which consists of the superconducting coil (SC), series transformer and diode bridge circuit. The diode bridge converts three-phase AC to DC current, which flows through the super- conducting coil. The current through the primary and secondary winding of transformer are defined as $i_{p}, i_{s}$, respectively, and the ratio of transformer is $\mathrm{N}$, as follows:

$$
\frac{i_{s}}{i_{p}}=N
$$

The SC current $\left(i_{d}\right)$ is almost equal to the peak value of the secondary current.

$i_{d}=\sqrt{2} i_{s}=\sqrt{2} N i_{p}$

After charging the SC and in the steady state condition, the current of SC is approximately constant and we have:

$$
V_{d}=L_{d} \frac{d i_{d}}{d t}=0
$$

Therefore, the impedance seen by the primary side of the coupling transformer is very low. Under the fault conditions, the current increases with a constant rate as shown in Fig. 4. The per-phase current is approximately given by the following equation [12].

$$
I_{p h}=\frac{V_{m}}{L}\left(1+i_{0}\right)\left(t-t_{0}\right) \cos (\omega t+\varphi) \quad t \geq t_{0}
$$

Where $V_{m}$ is the magnitude of the source voltage, $L_{d}$ is the inductance of the SC (referred to the primary side), $t_{0}$ is the fault starting instant, $\varphi$ is the phase angle and $i_{0=}$ $i\left(t_{=0}\right)$

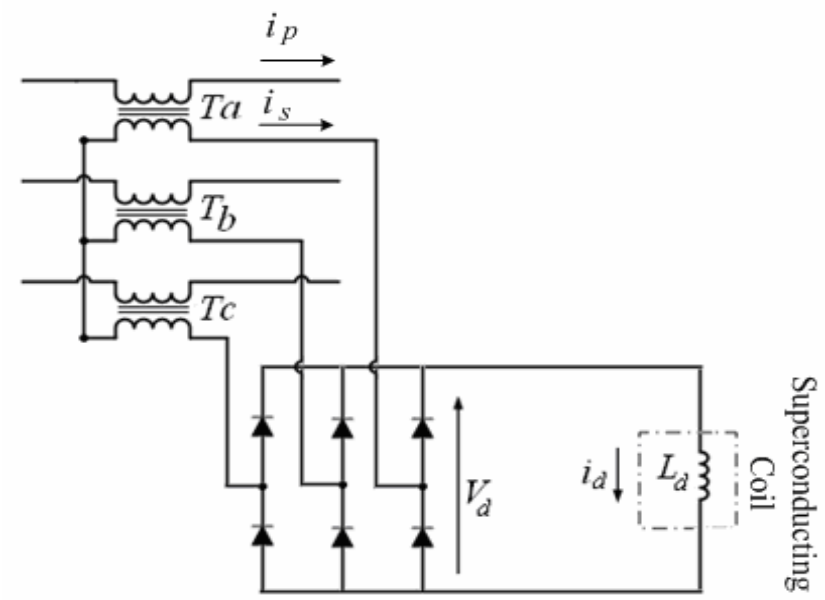

Fig. 3. Bridge-type SFCL schematic diagram 


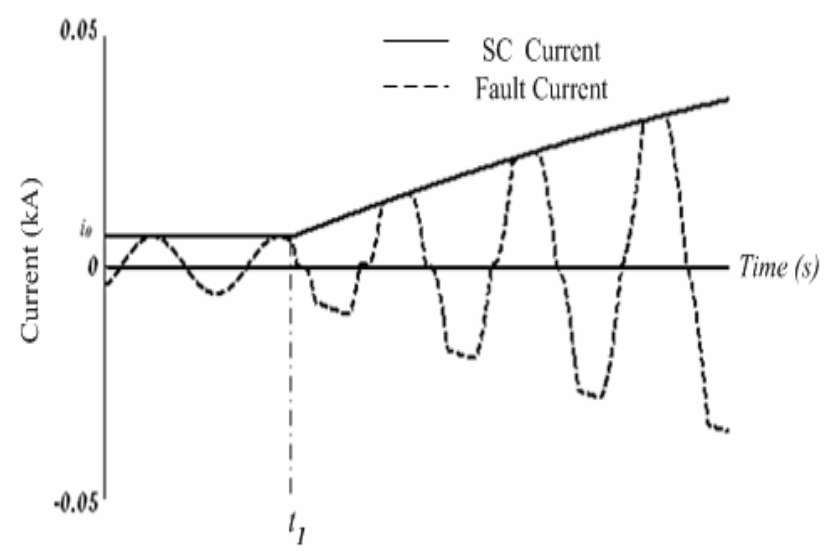

Fig. 4. SC and fault current during fault and normal operation with using bridge-type SFCL

\section{FCL in Distribution System}

Most of the distribution systems have radial form. As a result in any branch of a radial system, power only flows in one direction. The distribution voltage levels are in the range of $10 \mathrm{kV}$ to $30 \mathrm{kV}$. It can be expected that there will be interactions between the FCL and power system, if FCL is placed in the grid. A typical distribution system is represented in Fig. 5. The source impedance includes the transformer impedance and the upstream short-circuit impedance. Parallel feeders are connected to the Point of Common Coupling (PCC). The bus is supplied by a substation transformer from a $110 \mathrm{kV}$ network. The upstream source system is modeled as an infinite bus and the source impedance is consists of an equivalent resistance and inductance connected to the local distribution substation. The load is modeled as a lumped series R-L-C branch with a power factor of 0.886. A 3phase short circuit fault is simulated at the load side, on feeder 2 (F2), as shown in Fig. 5. After one cycles, the circuit breaker opened to clear the fault. The circuit breaker is modeled as an ideal time-controlled switch with a parallel capacitance. This capacitance is the total capacitance of the source side circuit, which includes the stray capacitance of circuit breaker to the ground.

\section{Simulation Results}

The simulation has been carried out with a fault starting at $\mathrm{t}=140 \mathrm{~ms}$. The circuit breaker has been opened after 1 cycle.

The total simulation time was $200 \mathrm{~ms}$ according to the circuit breaker opening time, and the simulation step is $1 \mu \mathrm{s}$. The parameters for the simulation have been listed in table 1 .

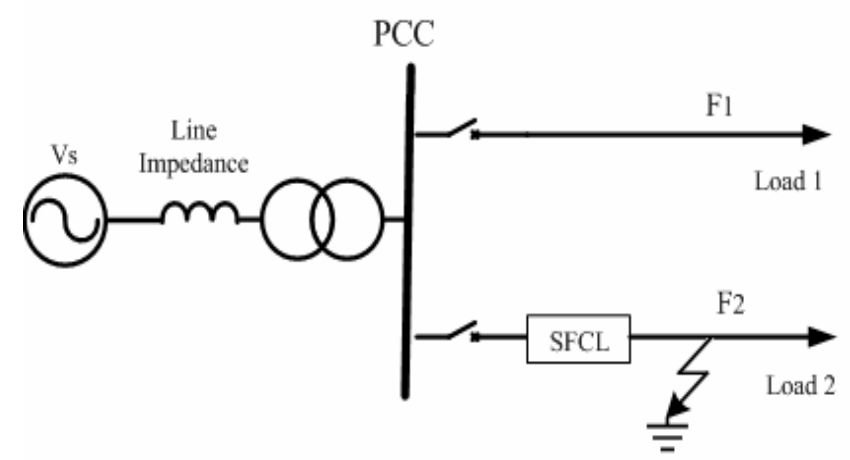

Fig. 5. Schematic diagram of study system

TABLE I. SYSTEM PARAMETERS

\begin{tabular}{|c|c|c|}
\hline \multicolumn{2}{|c|}{ PARAMETER } & VALUE \\
\hline \multirow{2}{*}{ Supply } & Voltage & $110 \mathrm{kV}, 50 \mathrm{~Hz}$ \\
\cline { 2 - 3 } & $\begin{array}{c}\text { Step down } \\
\text { Transformer }\end{array}$ & $110 / 15 \mathrm{kV}, 10 \mathrm{MVA}$ \\
\hline $\begin{array}{c}\text { Bridge- } \\
\text { type FCL }\end{array}$ & Inductance of SC & $50 \mathrm{mH}$ \\
\hline \multirow{2}{*}{$\begin{array}{c}\text { Inductive } \\
\text { SFCL }\end{array}$} & Inductance $\left(\mathrm{L}_{\mathrm{FCL}}\right)$ & $64.4 \mathrm{mH}$ \\
\cline { 2 - 3 } & $\begin{array}{c}\text { Stray Capacitance } \\
(\mathrm{Cp})\end{array}$ & $1 \mathrm{uF}$ \\
\hline \multirow{2}{*}{$\begin{array}{c}\text { Resistive } \\
\text { SFCL }\end{array}$} & $\begin{array}{c}\text { Maximum } \\
\text { Resistance }\left(\mathrm{R}_{\max }\right)\end{array}$ & $20 \Omega$ \\
\hline \multirow{2}{*}{ Load } & Load 1 & $\mathrm{P}=6 \mathrm{~kW}, \mathrm{PF}=0.9$ \\
\cline { 2 - 3 } & Load 2 & $\mathrm{P}=5 \mathrm{~kW}, \mathrm{PF}=0.88$ \\
\hline
\end{tabular}

When the circuit breaker attempts to interrupt the limited fault current, an over voltage is developed across contacts [13]. This voltage is called Transient Recovery Voltage (TRV) of the circuit breaker. Circuit breakers may fail to interrupt fault currents when power systems have transient recovery voltage levels, which exceed the rating of circuit breakers. The Rate of Raise of Recovery Voltage (RRRV) is an important parameter in the power system operation, presented in IEEE C37.41 standard. The simulations by the Electro-Magnetic Transients Program (ATP-EMTP) was performed to determine the instantaneous values of the transient recovery voltage $V C B$ appearing after current zero and the current flowing $I_{C B}$ through the contacts of the circuit breaker before current zero for following cases:

\section{A. Without Using Any FCL}

Fig. 6 shows the current flowing through the contacts of the circuit breaker before current zero without FCL application. It is obvious in Fig. 6, which the peak value of the fault current is about $3500 \mathrm{~A}$, which can damage the system devices. Fig. 7 shows the circuit breaker's TRV without installation of FCL. The TRV in the absence of the FCL reaches a peak value of $24 \mathrm{kV}$. The initial transient recovery voltage (ITRV) in the absence of the FCL reaches a first peak value of $23.7 \mathrm{kV}$ during $0.0044 \mathrm{~s}$. From these values, the RRRV was determined to be $55 \mathrm{kV} / \mathrm{us}$. 


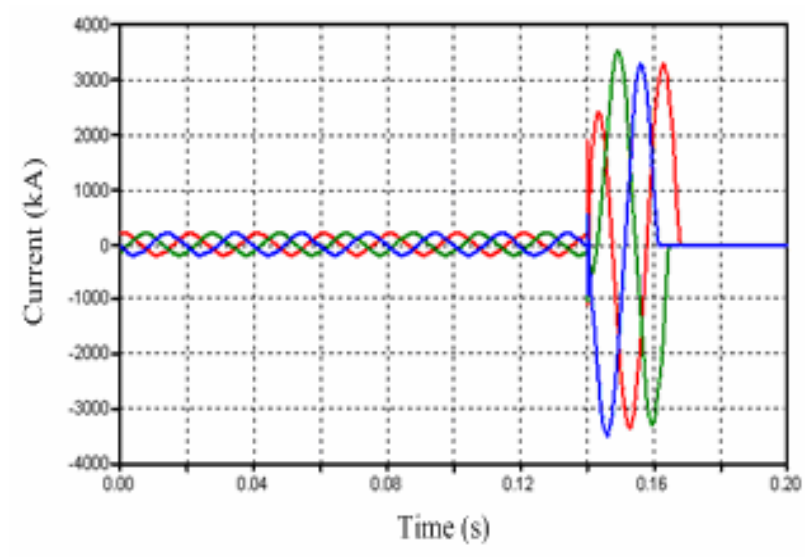

Fig. 6. Circuit breaker current without using any FCL

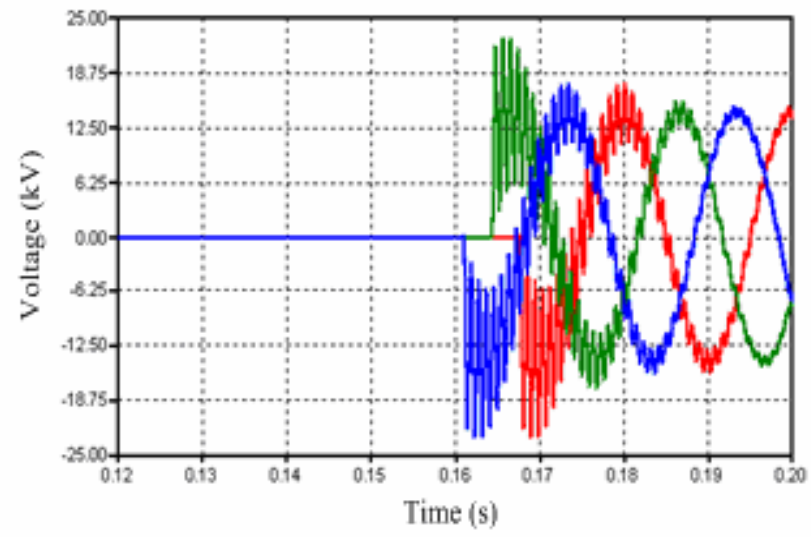

Fig. 7. Circuit breaker TRV without using any FCL

\section{B. With Using Inductive SFCL}

Fig. 8 shows the current flowing through the contacts of the circuit breaker before current zero with inductive SFCL application. It is obvious in Fig. 8, which the peak value of the fault current is limited about $800 \mathrm{~A}$. Application of inductive SFCL creates an asymmetrical short-circuit current. Fig. 9 shows the circuit breaker's TRV with application of inductive SFCL. The TRV reaches a peak value of $30 \mathrm{kV}$. The initial transient recovery voltage (ITRV) with inductive SFCL reaches a first peak value of $10 \mathrm{kV}$ during $0.00004 \mathrm{~s}$. From these values, the RRRV was determined to be $250 \mathrm{kV} / \mathrm{us}$.

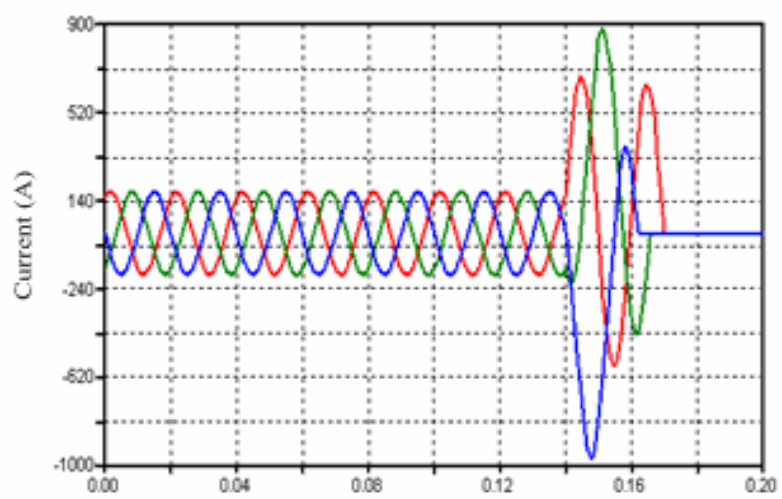

Fig. 8. Circuit breaker current with using inductive SFCL

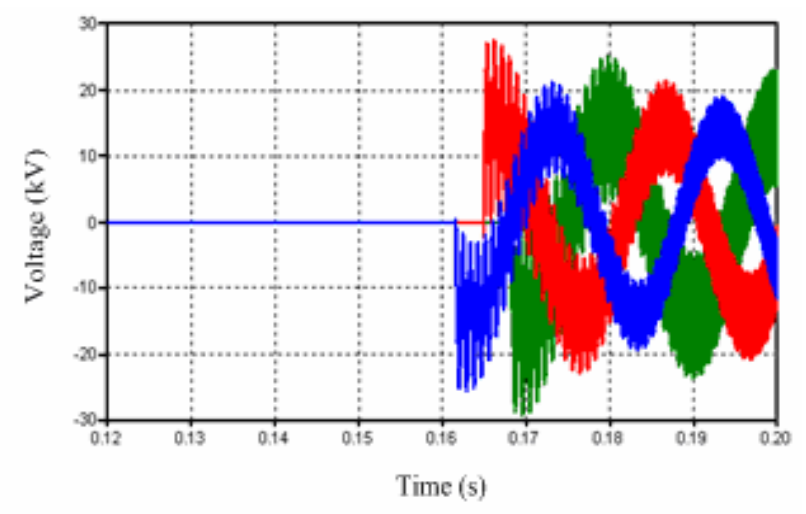

Fig. 9. Circuit breaker TRV with using inductive SFCL

\section{With Using Resistive SFCL}

Fig. 10 shows the current flowing through the contacts of the circuit breaker before current zero with resistive SFCL application. It is obvious in Fig. 10, which the peak value of the fault current is limited about 650A. Application of resistive SFCL eliminates the asymmetrical component of fault current. Fig. 11 shows the circuit breaker's TRV with application of resistive SFCL. The TRV reaches a peak value of $16 \mathrm{kV}$. The initial transient recovery voltage (ITRV) with inductive SFCL reaches a first peak value of $7 \mathrm{kV}$ during $0.0009 \mathrm{~s}$. From these values, the RRRV was decreased to $8 \mathrm{kV} / \mathrm{us}$.

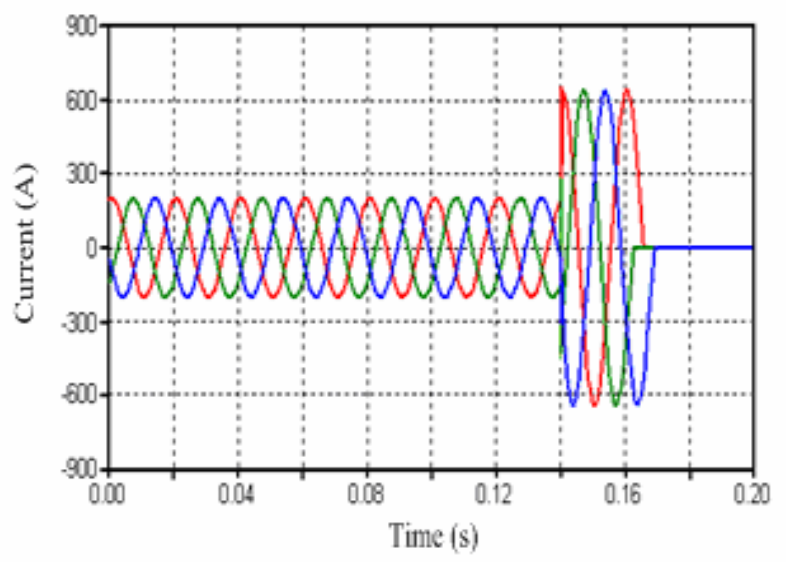

Fig. 10. Circuit breaker current with using resistive SFCL

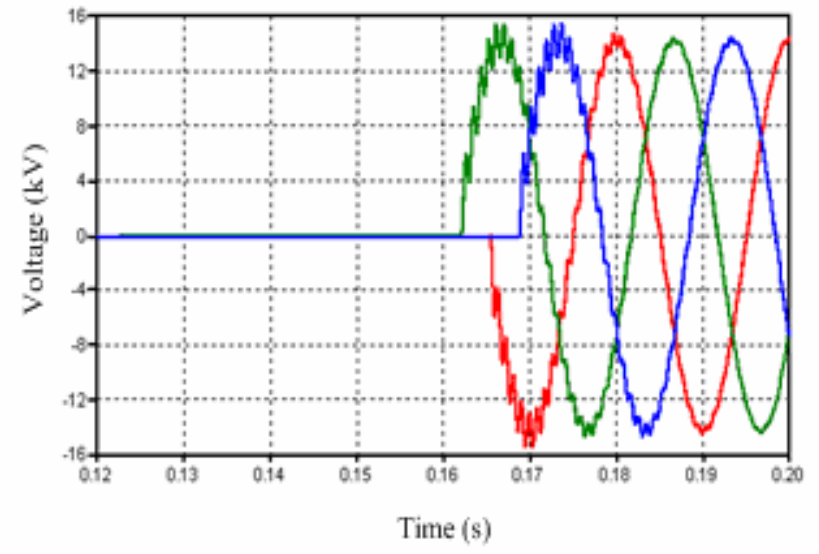

Fig. 11. Circuit breaker TRV with using Resistive SFCL 


\section{With Using Bridge-SFCL}

Fig. 12 shows the current flowing through the contacts of the circuit breaker before current zero with bridge-type SFCL application. It is obvious in Fig. 12, which the peak value of the fault current is limited about $450 \mathrm{~A}$, but the fault current increases with a constant rate. Fig. 13 shows the circuit breaker's TRV with application of bridge-type SFCL. The TRV reaches a peak value of $20 \mathrm{kV}$. The initial transient recovery voltage (ITRV) with inductive SFCL reaches a first peak value of $7.5 \mathrm{kV}$ during $0.00029 \mathrm{~s}$. From these values, the RRRV was decreased to $24 \mathrm{kV} / \mathrm{us}$.

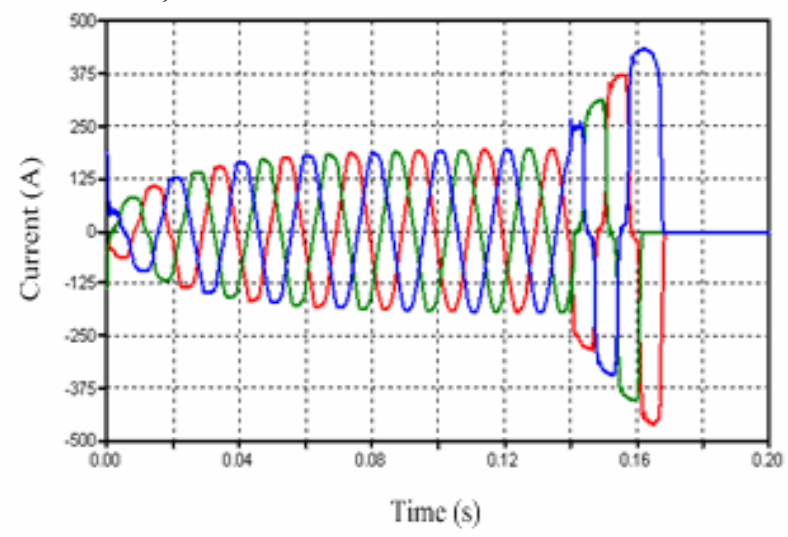

Fig. 12. The Circuit Breaker Current with Using Bridge-Type SFCL

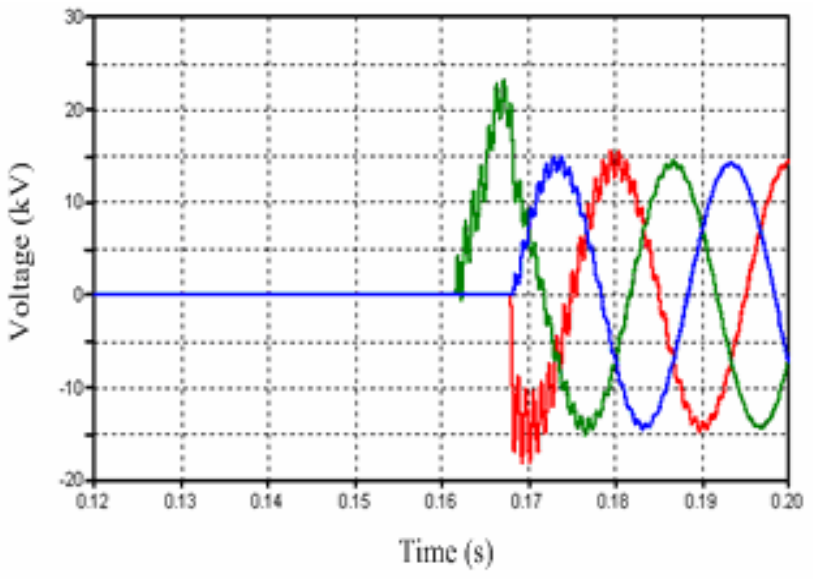

Fig. 13. The Circuit Breaker transient Recovery Voltage with using Bridge-Type SFCL

\section{Conclusion}

In this paper, the effect of three types of SFCL on transient recovery voltage of circuit breaker has been studied. The simulation results show that not only fault current has been limited, but also the TRV and RRRV of the circuit breaker has been reduced effectively by using the resistive SFCL and bridge type SFCL. By using inductive SFCL, the fault current has been limited, but the TRV and RRRV of the circuit breaker has been increased. Also, by using the resistive SFCL, the TRV and RRRV of circuit breaker was lower than the other types of SFCL.

\section{References}

[1] Hector G.Sarmiento, R.Pampin, "An Example in Controlling Short Circuit Levels in Large Metropolitan Area," Power Engineering Society General Meeting, IEEE, Vol.2, June 2003
[2] CIGRE WG A3.10, "Fault Current Limiters Report on the Activities of CIGRE WG 3.16,"CIGRE Technical Brochure, 2006.

[3] CIGRE WG A3.10: "Fault Current Limiters in High Electrical Medium and Voltage Systems", CIGRE Technical Brochure, No. 239, 2003.

[4] E.Calixte, Y.Yokomizu, T.Matsumura and H.Fujita, "Reduction in Severity of Circuit Breaker Duty Under Generator-Fed Fault Condition by Means of Resistive Fault Current Limiter," International Journal of Power Energy System, Power Con Special Issue 2004, pp.24-31

[5] L. Z. Lin, K.P. Juengst, "Application studies of superconducting fault current limiter in electric power systems ,’ IEEE Trans. Appl. Superconduct. 12 (March (1)) (2002) 900903.

[6] K. Arai, H. Tanaka, M. Inaba, H. Arai, T. Ishigohka, M. Furuse, and M. Umeda, "Test of Resonance-Type Superconducting Fault Current Limiter," IEEE Trans. Appl. Supercond., Vol.16, No. 2, June 2006

[7] S.H. Lim, H.S. Choi, and B.S. Han, "Fault Current Limiting Characteristics of DC Dual Reactor Type SFCL Using Switching Operation of HTSC Elements," IEEE Trans. Appl. Supercond., Vol.16, No. 2, June 2006.

[8] M. C. Ahn, H. Kang, D. K. Bae, D. K. Park, Y. S. Yoon, S. J. Lee, and T. K. Ko, "The Short-Circuit Characteristics of a DC Reactor Type Superconducting Fault Current Limiter With Fault Detection and Signal control of the Power Converter,'IEEE Trans. Appl. Superconduct., Vol. 15, No. 2, June. 2005

[9] B. Gromoll, G. Ries, W. Schmidt, H.-P. Kraemer, B. Seebacher, B. Utz, R. Nies, H.-W. eumueller, E. Balzer, S. Fischer, and B. Heismann, "Resistive fault current limiters with YBCO films-100 kVA functional model," IEEE Trans. Appl. Superconduct., vol. 9, pp. 656-659, Jun.1999.

[10] Lin Ye, K.P. Juengst, "Modeling and simulations of resistive type superconducting fault current limiter," IEEE Trans. Appl. Superconduct. 14 (June (2)) (2004) 839-842.

[11] A. Gyore, A. Szalay, V. Sokolovsky, and W. Gawalek, "Improved design and system approach of a three phase inductive HTS fault current limiter for a $12 \mathrm{kVA}$ synchronous generator," IEEE Trans. Appl. Superconduct., vol. 13, pp. 2000-2003, Jun. 2003.

[12] M. T. Hagh and M. Abapour, "Nonsuperconducting Fault Current Limiter With Controlling the Magnitudes of Fault Currents," IEEE Trans. Power Electronics, Vol.24, pp. 613619, March 2009

[13] E.Calixte, Y.Yokomizu, T.Matsumura and H.Fujita "Reduction of Rating Required for Circuit Breakers by Employing Series-Connected Fault Current Limiter,"Generation, Transmission and Distributin IEE Proceedings, pp.36-42, Jan 2004 